\title{
Improving the 3-D Spatial Visualization Skills of Women Engineering Students
}

\author{
Sheryl A. Sorby, Beverly J. Baartmans \\ Michigan Technological University
}

\begin{abstract}
Three-dimensional (3-D) spatial visualization ability is important to success in engineering studies. Unfortunately, studies show that 3-D spatial visualization skills of women often lag behind those of their male counterparts. In the fall of 1993, a course was developed at Michigan Technological University (MTU) to aid students in overcoming deficiencies in spatial visualization ability. This paper describes this course and presents some results from this study.
\end{abstract}

\section{BACKGROUND}

Traditionally, scientists and engineers have been white males, but there are compelling reasons to increase the number of women who choose engineering as a career. The engineering profession is faced with significant problems that need solutions. If we are to attract the best people to engineering, recruitment must occur from all of the population, not just from $50 \%$ of it. By increasing the number of women engineers, different perspectives and different solution methods will be proposed. In a study of the leadership qualities of men and women in executive positions, it was found that, "Executive women are more likely than executive men to move in new and original directions" 1 . Since executive positions more often go to employees coming from the technical ranks, increasing the number of women who study engineering should also, over the long run, increase the number of women executives in industry. The engineering profession and its image will be enhanced by greater participation of women. It may become a more caring and balanced profession that considers the impact of engineering designs and projects on society, the environment, and the health of individuals The abilities of women cannot be ignored if this country is to solve its problems. Unfortunately, the number of women who choose to study engineering is still only a fraction of the total number of engineering students, despite years of concerted effort to change this trend. Visualization skills are critical to success in engineering, but women are much more likely to have deficiencies in this area than are their male counterparts-5 This paper will focus on efforts at MTU to address these differences and enhance the ability of women to complete their engineering studies.

Spatial visualization ability develops in three stages according to Piagetian theory. In the first stage of development, children learn to distinguish a shape in relation to its surrounding environment. This stage of development is primarily concerned with two-dimensional shapes and nearly all children have achieved this level of spatial ability by the time they have started school. In the second stage of development, children learn to visualize what a three-dimensional object will look like from different viewpoints. This stage of development is usually achieved by the time students are in junior high school where students are correctly able to visualize what

This material is based upon work supported by the National Science Foundation under Grant No. DUE-9254207 
a familiar_object (e.g., a telephone) will look like from different perspectives. However, if the objects are unfamiliar, students will many times have difficulty with this type of visualization through their high school " years. The final stage of development occurs when an individual can visualize objects under some type of transformation of physical phenomena like length, area, or volume. Standardized tests have been created for the determination of an individual's ability to visualize at the first two stages of development. The Purdue Spatial Visualization Test: Rotations ${ }^{\mathrm{b}}$ was developed to assess an individual's spatial ability at the second stage of development.

\section{PREVIOUS RESEARCH STUDIES AT MTU}

In 1985, one of the authors ${ }^{3}$ conducted a research study at MTU. The sample used in the study included 365 entering freshman (65 women and 300 men) who had declared Mechanical Engineering as their major. During freshman orientation, the students were given the Purdue Spatial Visualization Test: Rotations (PSVT:R). Figure 1 shows a sample problem taken from this exam. A multiple regression analysis established that a
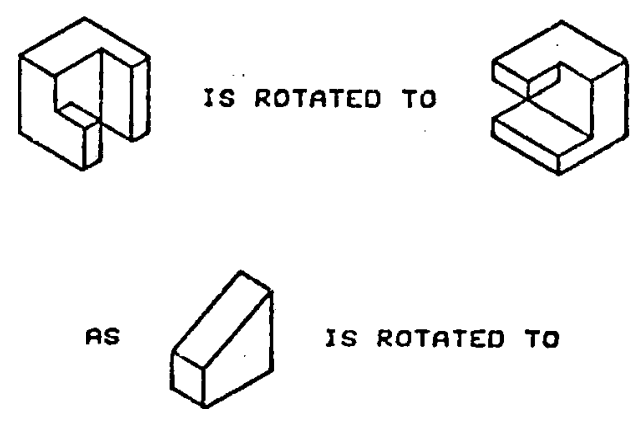

$$
\text { IS ROTATED TO }
$$

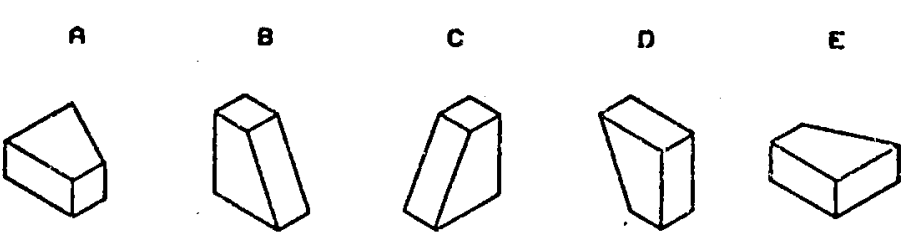

Figure 1

student's score on the PSVT:R was the most significant predictor of success in the freshman graphics course (ME103) out of the eleven predictors studied. The other factors which were found to be significant in predicting student success in ME 103 were math ACT test score and a combination of prior experience in shop, drafting and solid geometry. Of these significant variables, women lagged behind their male counterparts in two of the three-spatial visualization as tested by the PSVT:R and prior experience in drafting, shop and solid geometry. The mean score for women on the spatial visualization (20.9 out of 30) was significantly lower than that for men (24.2 out of 30). Furthermore, it was expected that students would improve their spatial visualization ability as a result of instruction and other activities in the freshman graphics course. In this study both genders did improve their performance on the spatial visualization test, however, the mean post-test score for women (23.3) was still significantly lower than that for men (25 .6). These results are shown in Figure 2.

\section{CURRENT PROJECT}

In January of 1993, the authors of this paper were awarded a curriculum development grant from the National Science Foundation to develop a course for the improvement of 3-D spatial visualization skills of freshman engineering students. The course (GN102) has a lecture as well as a computer laboratory component. 


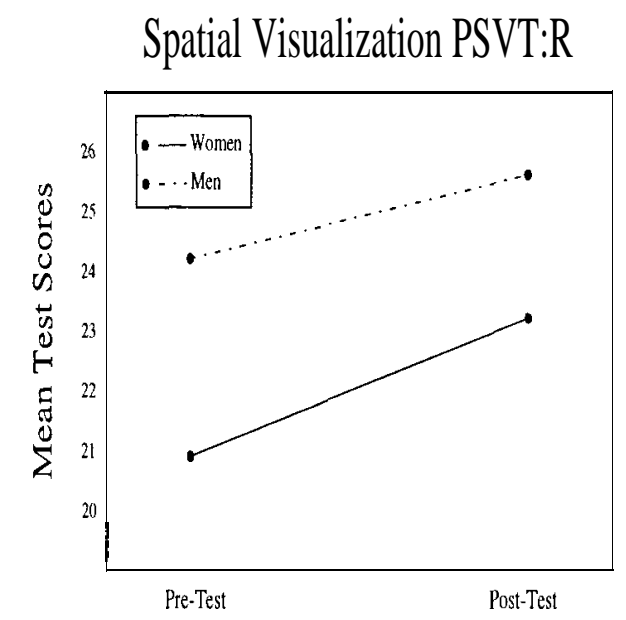

Figure 2

In the computer lab, solid modeling software is used to demonstrate 3-D concepts as an instructional aid in the development of visualization skills. As a part of the grant activity, a textbook, entitled Introduction to 3-D Spatial Visualization, computer lab manual and accompanying instructional aids were written and have been recently published by Prentice-Ha11 $1^{7}$.

During freshman orientation in the fall of 1993, the visualization ability of 535 students were tested using the PSVT:R exam. The students who were tested included those enrolled in Civil, Environmental, Mechanical and General Engineering. Unlike many other engineering programs in the nation, freshmen at MTU are admitted directly into degree-granting departments. However, a large proportion (approximately 40\%) of the freshman class enters without a declared major and is then placed in General Engineering. A greater percentage of women demonstrated deficiency in visualization skills than their male counterparts. Of the group which was tested, 22\% were women, but more than $40 \%$ of those failing the exam were women.

Of the students who failed the exam, a random sample of 50 students was selected for participation in the new course. The remainder of the students who failed the exam were selected to be a part of a control group. Because students could not be "forced" into taking the class, not all of those students selected for the course actually enrolled in it. The initial course had an enrollment of 27 students.

The course format consisted of two hours of lecture and two hours of computer lab instruction per week. MTU is on a quarter system academic calendar, so the course was offered during a 10-week term. Students were issued a set of snap cubes during the first week of the course so that they could actually "build" the 3-D models in many of the exercises. In addition, students purchased a packet of grid and dot paper which was used in the completion of in-class and homework exercises. A brief outline of the topics covered in the course follows:

Course Introduction.

Isometric and Orthographic Sketching.

Orthographic Drawings and Applications.

Pattern Development.

Two- and Three-Coordinate Drawing.

Translation and Scaling.

Rotation of Objects. 


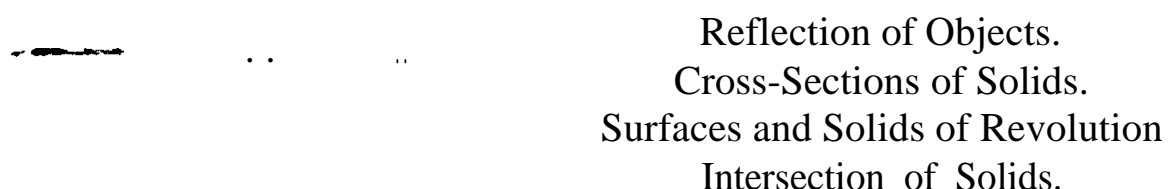

As a part of this curriculum development, computer exercises were developed which utilize I-DEAS software as a visualization tool. The exercises were written to adhere closely to the topics covered in the class.

\section{PROJECT ASSESSMENT}

Preliminary assessment of the project indicates promising results. As a part of the final exam for the course, the students were given the same PSVT:R exam that they had taken during freshman orientation. The scores on this standardized exam showed marked improvement for the students in the class. At the end of the course the average score on the PSVT:R was $86 \%$ compared to $51 \%$ before the course. A dependent t-test was used to analyze the students' gain scores on the PSVT:R. The test showed that statistical] y significant gains were made $(\mathrm{t}=12.53, \mathrm{p}<0.0001)$. Thus, it appears that the course is improving the spatial skills of the students as measured by this testing instrument.

The pre- and post-test results were also analyzed according to gender. In this analysis it was found that both the male and female students made significant gains in their scores on the PSVT:R. However, there was no statistical difference between the average gain score of the male students as compared to the average gain score of the female students. Table 1 summarizes the results of the statistical analysis. [Note: there were 30-pts possible on the PSVT:R]. The student performance in subsequent graphics courses was also analyzed. It was found that the average GPA for students enrolled in GN102 was 3.0 compared to an average GPA of 2.6 for the control group.

\begin{tabular}{|l|c|c|c|c|}
\hline & $\begin{array}{c}\text { Average } \\
\text { Pre-Test } \\
\text { Score } \\
\text { (S. Dev. })\end{array}$ & $\begin{array}{c}\text { Average } \\
\text { Post-Test } \\
\text { Score } \\
\text { (S. Dev. })\end{array}$ & $\begin{array}{c}\text { Average } \\
\text { Gain Scores } \\
\text { (S. Dev. })\end{array}$ & $\begin{array}{c}\text { Gain Score } \\
\text { t-test }\end{array}$ \\
\hline \hline Males & 15.45 & 25.45 & 10.00 & $\mathrm{t}=8.75$ \\
$(\mathrm{n}=11)$ & $(2.38)$ & $(3.80)$ & $(3.79)$ & $\mathrm{p}<0.0005$ \\
\cline { 2 - 2 }$(\mathrm{n}=13)$ & 15.54 & 24.00 & 8.46 & $\mathrm{t}=9.02$ \\
$\mathrm{pemales}$ & $(2.60)$ & $(4.00)$ & $(3.38)$ & $\mathrm{p}<0.0005$ \\
\hline
\end{tabular}

Table 1

Students were also asked to fill out a formative questionnaire at the end of the course. Overall, the student evaluations were favorable. The textbook itself had a rating of 4 on a 5-point scale. For the instructional aids used in the course, the students overwhelmingly approved of the use of snap cubes in the construction of buildings. They also thought that working out problems from sample handouts during class was a worthwhile activity.

The students were asked to comment about the class. The following is a compilation of some of the responses received. "It did teach me how to rotate things in my mind;" ". the xyz axis helped to visualize the 
rotations and made the class much easier;" "Learning stuff I had never been exposed to before was exciting;" "I . liked being able to-see things with the cubes;" and "Everything. I think it was very beneficial to me."

\section{CONCLUSIONS}

Previous research at MTU identified spatial visualization ability (as measured by the PSVT:R) to be the most important predictor of student success in freshman graphics (ME 103) at MTU. The course described in this paper was designed to prepare freshmen who are weak in 3-D spatial skills to compete more successfully in their engineering design classes and to be a first step toward the removal of inequities in important background differences between women and men. As evidenced by student gains on the PSVT:R, the experimental course has a significant, positive impact on student test scores. The student comments regarding the course have been generally positive and encouraging.

\section{REFERENCES}

1. McKee, Marie, "Increasing the Participation of Women in Engineering Careers: A Corporate Perspective," Proceedings of the 1991 WEPAN Conference, Washington, D. C., June 1991, 107-120.

2. Frize, M., "Women in Engineering in Canada," Proceedings of the 9th International Conference of Women Engineers and Scientists, Coventry, England, July 1991, 42D-45D.

3. Gimmestad, B. J. "Gender Differences in Spatial Visualization and Predictors of Success in an Engineering Design Course." Proceedings of the National Conference on Women in Mathematics and the Sciences. Eds, Sandra Z. and Philip Keith (St. Cloud, MN: St. Cloud State University September 1990.) 133-136.

4. Hier, D. B. and W. F. Crowley, "Spatial Ability in Androgen-Deficient Men," New England Journal of Medicine, May 20, 1982,306, No. 20, pp. 1202-1205.

5. Fennema, E. and J. A. Sherman, "Sexual Stereo-typing and Mathematics Learning," The Arithmetic Teacher, May 1977,24, no. 5, pp. 369-372.

6. Guay, R.B. Purdue Spatial Visualization Test: Rotations. West Lafayette: Purdue Research Foundation, 1977.

7. Baartmans, B. G., and S. A. Sorby, Introduction to 3-D Spatial Visualization, Prentice-Hall, Englewood Cliffs, NJ, 1996.

\section{BIOGRAPHICAL INFORMATION}

SHERYL A. SORBY received a PhD in Mechanical Engineering from Michigan Technological University in 1991. As a PhD candidate, she taught freshman graphics courses and computer aided design. She currently is an Assistant Professor in the Civil and Environmental Engineering Department at MTU. Her research and teaching interests are in the areas of computer visualization and experimental mechanics.

BEVERLY J. BAARTMANS is an Associate Professor of Mathematics at Michigan Technological University. She has a Ph.D. in Math Education from the University of Colorado at Boulder. Her research interests include mathematical problem solving strategies, incorporation of computing devices into the teaching and learning of mathematics and the development of 3-D spatial visualization ability. 